\title{
A Study of English Phonetic Teaching Strategies From the Perspective of Embodied Cognition
}

\author{
Xinzhu Liu \\ School of Foreign Languages and Literatures, Chongqing Normal University, Chongqing, China
}

\begin{abstract}
The mastery of language is inseparable from obtaining phonetic knowledge, and forming correct pronunciation is one of the necessary conditions for learning languages. Good English pronunciation can promote the learning of listening and speaking. English phonetic knowledge is so abstract to grasp that in primary schools, combining the characteristics of children's cognitive development, English teachers should mobilize students' body and mind to learn together, and construct embodied teaching situation to guide students to form standardized pronunciation gradually through the process of interaction between their body and environment. So that students will lay a solid phonetic foundation for their oral communication in the future, and the comprehensive development of their comprehensive English quality will be promoted.
\end{abstract}

Index Terms — embodied cognition, primary English, phonetic teaching

\section{INTRODUCTION}

As the cornerstone of proficient oral communication skills, phonetic skills play a quite important role in English learning. According to the critical period hypothesis of language acquisition, the age of language acquisition has a critical period which affects the ability of language acquisition, and many studies of immigrants in natural acquisition environments have found the advantages of early acquisition.

In China, students in primary schools are in the initial stage of learning languages systematically, and are also in the critical period of acquiring the second language, English. They are good at imitating, and their concrete thinking skills have been developing stronger than abstract thinking skills, while English phonetic knowledge can be grasped by accumulating much experience from practice. In primary school English classes, however, compared with teaching vocabulary, grammar and other sections, many teachers don't pay much attention to phonetic teaching, and there are still many problems in this part at present. This essay starts from the perspective of cognitive psychology, applying the embodied cognition theory to English phonetic teaching in Chinese primary schools to tackle those problems, so as to let students devote their body and mind together to phonetic studying, and form phonetic skills step by step through their personal experience.

\section{BASIC IDEAS OF EMBODIED COGNITIVE THEORY}

As an emerging research trend in the field of cognitive science, embodied cognition is also known as "embodiment" and "embodied mind". Embodied cognitive theory belongs to the research category of cognitive psychology, which refers to the strong connection between physiological experience and psychological state. This theory expounds three main viewpoints (Ye, 2010): (1) the process of cognition is determined by the physical properties of our body; (2) the content of cognition is provided by the body itself; (3) the subject of cognition is our body, which is embedded in the external environment. According to traditional cognitive science, represented by Descartes' mind-body dualism, it is widely believed that cognition is "disembodied", which means that cognition can exist independently out of our body. That is to say, during the learning process, our body is just the "container" of our mind, and does not directly participate in the learning process. From the perspective of embodied cognition theory, cognition is "embodied", and the boundary between mental development and our body is not obvious. The process of cognition is not a pure psychological process, but a process of understanding the external environment both psychologically and physiologically, and our body plays an important role in this process (Lakoff \& Johnson, 1999). We perceive the environment through our body and gain cognition through the interaction between body and environment (Ye, 2010). It's also mentioned in Piaget's cognitive development theory that our mind originates from actions, which is the source of cognition and the mediator of the interaction between subject and object. In his point of view, Piaget pointed out that individuals and the environment are combined in an uninterrupted interaction, and the formation of cognitive schemata is the result of children's sensory-motor system acting on the world. Besides, it is also reflects the direct impact of the body's action in the environment on mental development from Dewey's "learn by doing" perspective. From his point of view, cognition is closely related to our body. The occurrence of cognition is based on the system of "brain-body-environment", and our body is the basis of cognition and the core of cognitive process. Cognition is formed on the basis of external experience gained from the connection between the body and the environment. Cognitive development depends on the experience provided by physical behavior. 
Compared with junior and senior high school students in China, Chinese elementary school students are not as good at abstract thinking as them, and their perception of external things is more inclined to direct sensory experience. They have strong imitation ability and rich body language, however, who usually need to think in a more specific way, and their thoughts are susceptible to their emotional changes. In consequence, when teaching in primary schools, English teachers can use more intuitive teaching methods to help students understand complex and abstract knowledge easily, in order to improve teaching efficiency. During the natural acquisition process of mother tongue, children usually mobilize both their body and mind to have a complex connection with the surrounding environment, which can promote the formation and development of their linguistic logical thinking. This process reflects the typical characteristic of embodiment. As a result, in English class, teachers often imitate how children acquire their mother tongue to construct language teaching situations artificially, and let students participate in it wholeheartedly to learn English in the interaction between body and situation.

\section{Problems in English Phonetics Teaching in Chinese Primary Schools}

\section{A. Negative Transfer Effects of Mother Tongue}

According to the theory of cognitive structure migration and language transfer, language transfer refers to a common phenomenon in the process of second language acquisition in which students attempt to express their thoughts with the pronunciation, structure, semantics, or culture of the mother tongue when communicating in the foreign language. Language transfer can be divided into three cases (Zhang \& Xu, 2018): positive transfer, negative transfer and zero transfer. As there has been formed a reaction system of mother tongue, when students learn second language, they need to build up a new one, and these two different reaction systems can effect each other sometimes. For instance, the old one can have positive (or negative) transfer effects on the new one when their language structures are similar (or different). Affected by the living environment that regards Chinese as the mother tongue and the phonetic rules of Chinese Pinyin, the negative transfer of Chinese is quite prominent when Chinese primary school students obtain English phonetic knowledge.

According to the classification of the linguistic system, Chinese belongs to the Sino - Tibetan language family, which is a kind of tone language. And English belongs to the Indo-European family. It is a kind of intonation language. In Chinese English classes, when elementary school students study how to pronounce phonemes, they often use the pronunciation part of Chinese to pronounce, which leads to nonstandard English pronunciation. In addition, the pronunciation of certain phonemes may be easily confused where people mostly speak dialects in their daily life. For instance, according to the pronunciation of $[\theta]$ and [ð], students who come from Sichuan province or Chongqing may easily misread mouth as [maus] and misread that as [zæt]. There are also some students who want to "take shortcuts": using the pronunciation of Chinese Pinyin to help memorize the pronunciation of English words instead of directly pronouncing it in English. For example, cat is pronounced as [karte] instead of [kæt], face is pronounced as [feIsI] instead of [feIs], pencil is pronounced as ['pensəu] instead of ['pensl] etc.. In terms of rhythm, Chinese is a language with syllable timing, and its rhythm is expressed as staccato sound, while English is a language of accent timing, and its rhythm is expressed as legato sound. As children who have just entered primary schools have formed relatively mature rhythm principles of Chinese speaking, so that it is quite difficult for them to grasp the pattern of changes in stressed and unstressed sounds of English phonetics when reading texts or practicing dialogues.

\section{B. Lack of Systematicness in Phonetic Teaching}

The main objective of English phonetic teaching is to have students form correct and normative pronunciation, so as to help them communicate in English fluently. In China, it is found that there is almost no systematic phonetic knowledge arranged in primary English textbooks, though the curriculum standards have made clear requirements for phonetic learning. For instance, in English published by FLTRP, activities in each unit are mostly set as reading or listening activities. However, only activities like Repeat the pronunciation of letters, Sing the songs are related to phonetic learning. In English published by PEP, each unit is arranged around one theme, setting ten different modules: Let's try, Let's talk, Let's learn, Ask and answer, Let's spell, Match and say, Read and write, Let's check, Let's wrap it up and Story time, while there is no module directly related to phonetic knowledge. In Junior New Concept English published by FLTRP and Longman Press, there are nine modules in each unit: Listening and Understanding, New words and expressions, Notes on the test, Guided conversation, Pronunciation, Pattern practice, Written exercises, Listening, Match the questions and answers. Only Pronunciation is closely related to phonetic knowledge, which just involves comparison between similar phonetic symbols.

Although a large number of listening and reading activities can promote the formation of standard oral English to some extent, in real English classes, teachers hardly plan phonetic teaching in reading or listening activities. And affected by the arrangement of textbooks and special testing mode in China, it is of low enthusiasm for teachers to pay much attention to phonetic teaching. When learning English, it is impossible for students to understand deeper about what they learn only through textbooks. And compared with words and phrases and grammar, phonetic knowledge is more abstract. However, it is observed that teachers in Chinese English classes hardly make phonetic teaching plans systematically, some of who just simply regard phonetic teaching as phonetic symbol teaching, paying too much attention to how to pronounce new words but ignoring intonation, sense group and other parts of phonetic knowledge. 


\section{English Teachers'Unequal Phonetic Quality}

Different from vocabulary and grammar, phonetic knowledge is not only conceptual but also strong-practical. In China, students have very limited time and space to learn or use English, most of which is in English class. Chinese English teachers usually use listening training, tape reading, natural spelling and other traditional methods to help students enhance students' phonetic skills. However, only after accumulating enough oral practice experience can students truly master those skills. During language learning process, imitation is one of the necessary procedures. In non-English Speaking countries, represented by China, available English phonetic material is finite, and students may unconsciously imitate their teachers' pronunciation habits in the classroom. But the phonetic quality of English teachers in China varies in different regions. It was found that over half of teachers had hardly received standard phonetic training or normal phonetic teaching training in school. Some teachers' phonetic quality is not high enough to meet the requirements of the new curriculum standard. In addition, compared with oral communicative competence and emotional attitude of learning phonetics, some teachers pay more attention to students' ability to spell words and read texts aloud. In this condition, little effort is spent on training their own phonetic skills. As teachers are the direct mock object of students, their high phonetic quality can lay a good foundation for helping build up students' oral English ability in the future. On the contrary, teachers' incorrect low phonetic quality will easily make students confused, and greatly affect the accuracy of students' pronunciation. The elementary school stage is the enlightenment stage for students to improve their phonetic skills. But it is observed that phonetic teaching methods in real English classes are so monotonous and mechanical that only listening and speaking training are used to help students gain new knowledge, and students will easily get tired and lose interest in obtaining phonetic knowledge. What's worse, it will take much time and energy to correct students' pronunciation in the future once their non-standard speech habits are formed in this stage.

\section{Primary English Phonetic Teaching Strategies from the Perspective of Embodied Cognition}

\section{A. Construct Phonetic Knowledge in Mind Actively by Discovery Learning from Direct Experience}

From the perspective of cognitive assimilation learning theory, whether students can acquire new information or not mainly depends on the existing concepts in their cognitive structure. In language acquiring and studying process, the mother tongue is the earliest language learned by children. When studying other languages, students are affected by their mother tongue to varying degrees. At the elementary school level, teachers should take a full account of students' cognitive level and mental ability and make scientific plans for phonetic teaching. They can take advantage of students' basic familiarity with the pronunciation rules of their mother tongue, presenting both Chinese and English phonetic knowledge from multiple channels (such as auditory sense, visual sense, tactile sense etc.), guiding students to find out and summarize the similarities and differences from direct and personal experience, so as to give play to the positive transfer effects of mother tongue and eliminate its negative effects.

When teaching phonetic symbols, those with similar pronunciation can be listed to make comparisons. Teachers can ask students to prepare a mirror in advance to visualize their pronunciation, so as to experience directly how to pronounce and make corrections timely. When learning the pronunciation of the long vowel [i:] and the short vowel [I], many Chinese students usually equate the two vowels with the pronunciation of "yi" in Chinese Pinyin, and mistakenly believe that [i:] and [I] are only pronounced differently in length. When teaching these two vowels, teachers can use dynamic pictures of mouth shapes and tongue positions to explain how to pronounce. Students can imitate the pronunciation and correct it when looking at the mirror, finding out the shapes of their mouth and tongue positions. Peer correction can also be added when making contrastive practice. After repeated practice and corrections can phonetic memory points be formed on their mouth and tongue gradually, so that students can pronounce these vowels accurately when meeting them in the future. When teaching how to divide sense groups, teachers can make teaching plans from reading, listening and speaking aspects. According to Vygotsky's ZPD theory, there must be a gap between children's current development level and their potential development level, which is named as zone of proximal development (ZPD). Hence, teachers should take into full consideration about students' ZPD, giving proper support to help promote their development. On account of primary students' weak text reading ability, teachers can prepare two editions of one short passage-- Chinese edition and English edition-- to help students understand better about how to divide sense groups. The first step, presenting students with the Chinese one and let them punctuate sentences according to their existing experience. Next, showing them the English one and playing the tape, asking them to divide sense groups while listening to the tape. After correcting answers, teachers organize the whole class to compare the similarities and differences of division of sense groups between the two editions and conclude the rules. Then, students can work in groups to practice reading the short passage by playing the sentence chain, so that they can understand better the rules.

\section{B. Acquire Phonetic Perceptual Experience from the Common Experience of Body and Mind}

On the basis of embodied cognition theory, the subject of perception is our body, and we acquire perceptual experience from a joint experience of our body and mind. Though in Chinese primary English textbooks there aren't arranged many sections to train students' phonetic skills, teachers should neglect this part. Different from reading or writing, if someone wants to improve his/her phonetic skills, he/she should open his/her mouth and practice repeatedly. As a result, when making teaching plans, teachers need to consider how to mobilize the studying enthusiasm of each 
student and lead them fling themselves into studying.

With respect to rhythm, intonation and stress teaching, teachers can integrate them into different teaching procedures. For instance, in the warming-up stage, in comparison to Q\&A or free talk, rhythmic English songs or nursery rhymes can be used to form students' rhythm sensation. Students in class should sing songs and tap feet to the music, from which can they have an initial understanding of the new lesson and feel the prosodic features between lyrics concretely. When words and phrases with obvious changes in rhythm, stress and intonation, teachers can sort them out and lead students spell together and make gestures: from unstressed sound to stressed sound, swipe hands down; from stressed sound to unstressed sound, swipe hands up, and so on. When teaching logical stress principles in sentences, similar activities can be organized to help students understand how stress influences the meaning of sentences. In liaison teaching, after explanation of general rules of liaison, teachers can hold role-play competitions: Divide students into two groups, show some words on the slide and ask each student in each group represents one letter of each word. Students in each group can combine into a word are hand in hand. Then the teacher makes a sentence with those words, students whose letters' sound can be linked to each other should join their hands, and which group does faster and more correct can win the competition. Though knowledge in textbooks is fixed, teachers can crystallize abstract knowledge to help students understand intuitively and apply what they learn flexibly.

\section{Make Good Use of Digital Teaching Technology and Resources to Help Build up Embodied Teaching Situation}

In the era of the fifth-generation, digital teaching methods have matured and penetrate in the area of education in many forms. On the basis of embodied cognition theory, our body is of situationality. That is to say, our body is not isolated, instead, it is "embedded" and is connected with the external environment. In English phonetic teaching classes in primary schools, if digital teaching technology and resources can be made good use of and can be combined with traditional teaching methods to construct embodied teaching situation, the interaction between students' body and external environment will be promoted and to a certain extent, the weakness of phonetic quality of some English teachers will be offset. When teaching students abstract phonetic knowledge, using traditional instructional media like slides and tapes still focuses on input instead of output, as students' body is restrained. In fact, English is a kind of practical subject that aims at training students how to communicate with others in English fluently and accurately in real situations. As a consequence, digital teaching technology and resources can be applied to create artificial situations to narrow the gap between mental representation and actual phenomenon.

In English classes, teachers should pay attention to the interactivity of language learning and make full use of high-tech resources to create language activities that can widely involve children. The state of the body affects the cognitive neural mechanism of the brain. Compared with the lack of connection between the body and the object of discourse, the discourse that represents the high connection between the body and the object is more understandable. Through teaching activities, therefore, teachers should widely add language activities, and let students participate in them and communicate with each other. Only in this way can the body construct the language knowledge learned in language activities further. As teachers' pronunciation is not accurate enough, and it is quite a waste of time and energy to check if every students grasp the correct pronunciation of each words. As a result, during the class, for instance, AI technology can be used to create a 3D phonetic teaching environment that is similar or complementary to the real teaching situation, providing flexible and effective phonetic practices, so as to stimulate students' senses and bring them perceptual and various learning experiences. Also, online teaching platform can be used to establish an online phonetic information database and intelligent scoring system for each student in the classroom. Through this platform, teachers can arrange online phonetic practice tasks appropriately, and students can continuously correct their own pronunciation according to the standard pronunciation provided by the platform, and after that the system will give them scores based on their pronunciation. After class, teachers can use the phonetic evaluation system to create a variety of evaluation situations to test whether students can correctly use the knowledge of intonation, stress and rhythm in different situations.

\section{CONCLUSION}

In fact, there is no shortcut to form standard pronunciation or grasp adept phonetic skills in a short time, which require students to gradually deepen their studies and accumulate experience in a long term. When making phonetic teaching plans, teachers should take into full consideration about students' cognitive characteristics and mental development principles, leading students' mind and body both participate in the learning process, and have students learn by discovering and construct knowledge in their mind actively through direct experience. Phonetic learning not only needs theoretical explanations, but also needs training repeatedly. At the elementary school level, Chinese English teachers should combine the current situation of teaching and digital teaching methods based on the cognitive characteristics and psychological development rules of children at this stage, making up for their own shortcomings and infiltrating phonetic teaching into daily English classes. Teachers should also enhance the interaction between students' whole body and the learning environment by creating situations that fit the reality of life, and transform the study of "using brain to learn" into "learning throughout the body", which will furthermore effectively give play to the superiority of embodied cognition theory, and guide students to gain a comprehensive perception of phonetic knowledge from their personal experience. 


\section{REFERENCES}

[1] Barsalou, L. W. (1999). Perceptual Symbol Systems. Behavioral and Brain Sciences, 22, 577-660.

[2] Bhela, B. (1999). Native Language Interference in Learning a Second Language: Explanatory Case Studies of Native Language Interference with Target Language Usage. International Education Journal, 2, 25-32.

[3] Casasanto, D. (2011). Different Bodies, Different Minds: The Body Specificity of Language and Thought. Psychological Science. New York: Cambridge University Press, 20(6), 378-383.

[4] Clark, A. (2011). Supersizing the Mind: Embodiment, Action and Cognitive Extension. New York: Oxford University Press.

[5] Ellis, R. (1985). Second Language Acquisition. Oxford : Oxford University Press.

[6] Fusar-Poli, P. \& Stanghellini, G. (2009). Maurice Merleau-Ponty and the "embodied subjectivity". Medical Anthropology Quarterly, 23, 91-93.

[7] Haosheng Ye. (2010). Embodied Cognition:A New Approach in Cognitive Psychology. Advances in Psychological Science, 18(05), 705-710.

[8] Huifen Zhang, Yaqin Xu. (2018). Language Transfer and Second Language Teaching. Journal of Foreign Languages, 04, 69-72, 34.

[9] Lakoff, G. \& Johnson, M. (1980). Metaphors We Live By. Chicago, IL: University of Chicago Press.

[10] Mark Rowlands. (2009). Extended Cognition and the Mark of the Cognitive Philosophical Psychology. 22 (1), 1-19.

[11] Sen Liu, Zijie Niu. (2018). An Empirical Research on the Improved Multidimensional Pronunciation Teaching Assessment Model. Foreign Language Learning Theory and Practice, 04, 62-68.

[12] Slepian, M. L., Weisbuch, M., Rule, N. O. \& Ambady, N. (2011). Tough and Tender: Embodied Categorization of Gender. Psychological Science, 22, 26-28.

[13] Thea I. \& V. Dermina. (2014). Embodied Cognition: Challenges for Psychology and Education. Procedia-Social and Behavioral Sciences, 12, 275-280.

[14] Thelen, E., Schoner, G, Scheier, C.L.B.Smith. (2001). The Dynamics of Embodiment: A Field Theory of Infant Preservative Reaching. Behavioral and Brain Sciences, 24, 1-86.

[15] Ying Qi. (2018). A Discussion on Teaching Strategies of English Phonetic Teaching in Primary School. Journal of the Chinese Society of Education, S2, 143-144.

Xinzhu Liu was born in Mianyang, China in 1997. She is now a postgraduate in the School of Foreign Languages and Literatures, Chongqing Normal University, Chongqing, China. Her research interests include cognitive linguistics and second language acquisition. 